This is an Accepted Manuscript of an article published by Assessment in Education:

Principles, Policy \& Practice. The full text is available online at

http://www.tandfonline.com/doi/full/10.1080/0969594X.2015.1105783

Published details:

Santiago Cueto, Juan León \& Alejandra Miranda (2016) Classroom composition and its association with students' achievement and socioemotional characteristics in Peru, Assessment in Education: Principles, Policy \& Practice, 23:1, 126-148, DOI:

10.1080/0969594X.2015.1105783

\begin{abstract}
(up to 150 words)
School composition is a topic that has gained increasing attention from researchers over the past few years, as it has been found that the socioeconomic characteristics of students are associated with their achievement. However, most research has been cross-sectional and carried out in industrialized countries. In this study we use parental education as a measure of classroom composition across schools in Peru, and find that there are high levels of segregation, especially at the extremes of the distribution. Using longitudinal data from the Young Lives study, we find that classroom composition was positively associated with achievement in mathematics and sense of belonging of students, and not associated with reading achievement or perception of security at school. We discuss these results and suggest that school composition is a relevant variable to include in descriptions of national educational systems in Latin America and as a context variable for results of achievement among students.
\end{abstract}

Keywords (up to 6): school composition, classroom composition, achievement, socioemotional characteristics, longitudinal studies, Peru. 


\section{Classroom composition and its association with students' achievement and socioemotional characteristics in Peru}

\section{Introduction}

In Peru, and several countries in Latin America, studies have repeatedly shown that there is a high correlation between students' individual socioeconomic characteristics and achievement (e.g., OECD, 2010), which has led to this educational system being described as highly unequal. Much less is known however about classroom and school composition effects on achievement. This is an important issue given the increasing prominence of this topic in the international literature; for example, classroom composition has been found to be associated with school management and policies as well as with achievement. In this study, we will first describe patterns of classroom composition across schools in Peru, making emphasis on socioeconomic diversity within and among Peruvian schools. The purpose of this analysis is to compare the variability in socioeconomic characteristics of students within and across schools. Our proxy for socioeconomic status will be parents' educational attainment. Parental education has been used in several studies of school composition (see below), but also found to be associated with educational achievement and cognitive development of children in the region (Schady, 2011). Second, we will explore if classrooms composition is associated with student achievement in reading and mathematics, as well as with two socioemotional variables: sense of belonging and sense of security at schools. In an egalitarian educational system, students' characteristics such as parental education should not be associated with learning; however, in a segregated educational system, parental education might be an additional determinant to influence achievement through a variety of educational paths.

In order to study the above issues, we will use a unique longitudinal database for Peru, coming from the Young Lives (YL) study (a description of the design is provided below). YL allows us to control for early socioeconomic characteristics and preschool academic abilities of students, as well as the educational levels of the peers of the YL students at school, thus helping us to estimate both classroom composition in schools nationally and its association with the outcomes of YL children. In the next section, we briefly review the international literature on school and classroom composition.

\section{Relevance of School composition}

The effects of school composition on achievement have been analyzed since the Coleman Report (Coleman et a1., 1966), which was a study carried out in the U.S. This report showed that school composition mattered for achievement, in particular for minority students. Since then, many studies have focused on school-related variables in order to explain student achievement. More recent studies and conceptualizations have suggested however that the characteristics of the student population attending any given school may also be closely related with their educational opportunities. For example, the characteristics (or composition) of the student body may be relevant in explaining student achievement when examined in association with school management, organization, resources, curricular offer, and peer influence (Thrupp, Lauder \& Robinson, 2002); these authors suggest that parental education is a key variable of school composition. According to Thrupp and Lupton (2006), internationally an association has been found between contexts (which include socioeconomic composition of the student body), resources available and educational processes implemented at school. According to these authors, ignoring this would prevent from advancing in social justice issues. Thus they suggest a line of research on school composition, which would have implications for policy and practice.

For developing countries, many studies have analyzed the link between socioeconomic factors of students and achievement, both individually and using averages of school composition as determinants of achievement, and found a positive association (for example Fernandez, 2003, for Mexico; and Duarte et al., 2010, for the region). Jenkins et al. (2006) performed an analysis about 
school segregation for 27 OECD countries using data from PISA 2000 and 2003. They used different proxies for school segregation (e.g., student's socioeconomic status and parental education) and they found heterogeneity across OECD countries, with countries such as the United States, Hungary and Czech Republic showing higher segregation indexes. For Latin America, we have found only one study that explores school segregation in educational settings: Benavides, Leon \& Etesse (2014) used 2002 and 2009 PISA data to compare changes in school segregation over time in Argentina, Brazil, Chile, Mexico and Peru. The authors used the average student's socioeconomic status per school as a proxy of segregation. They found that over time, school segregation increased in Mexico and Peru, while Brazil, Chile and Argentina maintained or decreased their level of school segregation. We suggest that analysis of segregation over time are relevant for understanding the context in which students learn, plus this has implications for student learning. The next section presents some studies that have found an effect of school and classroom composition on student learning.

\section{The effect of school and classroom composition on students' outcomes}

The effect of school composition, more specifically of the characteristics of the students and their families, has been the subject of increasing analysis. Willms (2010) for example has analyzed the level of segregation among schools. He refers to horizontal segregation as the "extent to which students from different SES backgrounds are distributed unequally across schools" (p. 1011). Vertical segregation on the other hand refers to "the variation among schools in their performance that arises from early selection or the tracking of students into particular schools or school programs" (p. 1011). Willms analyzed performance of science in the PISA international evaluation, and found a positive and significant association between the two $(r=0.64)$. In this cross-country analysis, he concluded that "most successful countries have low levels of horizontal segregation" (p. 1027), and this would be due to classroom and school context variables (e.g., curriculum coverage and school resources), which would be of high quality for all.

In other studies there is evidence showing that horizontal segregation in the student body is associated with student achievement. For example, Caldas and Bankston (1997) in the U.S. used parental education as a measure of socioeconomic status and found that it had a significant impact on the achievement of students. In Belgium, Opdenakker and van Damme (2001) found that socioeconomic status (estimated through parental education) had an effect on school processes (e.g., school goals and teaching practices), and both in turn had significant effects on mathematics achievement. In a study in Denmark, Rangvid (2003) explored the effect of peers, measured by average parental education, on student achievement using quantile regressions. She found significant effects, which were stronger in low achievers. McEwan (2003) performed an analysis for Chile and found that parental education (especially maternal) had an effect on individual achievement in Spanish and mathematics. Van Ewijk and Sleegers (2010) carried out a metaanalysis of the effect of peer socioeconomic status on student achievement. The 30 studies they analyzed included two countries from Latin America (Chile and Bolivia); they found an average weighted effect size of 0.32 , but emphasized that among studies there was inconsistency in the definition of variables, designs and methods, which could potentially bias the results of any single study. They also suggested the importance of including previous achievement levels in any analysis of classroom composition. Lastly, they did not find significant differences among areas of achievement (i.e., language, mathematics or science) nor among countries.

Vertical segregation has also been studied over the past few decades as well. In the U.S., Hanushek et al. (2003) used a fixed effects models and found that studying with peers of higher mean levels of ability had a positive impact on achievement (no impact however of the variability of peers' abilities). Also, Burke and Sass (2008) in the U.S. used a longitudinal design, which allowed to control for individual and teacher fixed effects, and found significant non-linear effects of peers on achievement. Zimmer and Toma (2000) performed an analysis across five countries or regions (i.e., Belgium, France, New Zealand, Ontario and the U.S.), and found that students' abilities as well as socioeconomic status had an impact of achievement; this impact however was 
higher among students with lower levels of ability. Lastly, in Peru, only one study has been found, which used a cross-sectional design using a national data base of achievement, and found a positive and significant effect of peers on students' mathematics achievement (Agüero and Cueto, 2004). The authors suggest that increasing the variability of classrooms could have a positive effect on national averages.

\section{Study Objectives}

This paper has two objectives. The first is to determine the level of horizontal segregation in Peruvian classrooms across schools. For this we use standard quantitative indicators, and compare these with results from industrialized countries (we could not find comparable indicators for Latin America). Second, we explore if classroom composition is associated with student achievement (reading comprehension and mathematics) and socioemotional measures (sense of belonging and perception of school security). Based on the above literature, we hypothesize that children who attend classrooms with peers whose parents are more educated will score higher on achievement tests; however, we have found no previous studies of school composition effects on socioemotional measures. We still include them as it is reasonable to assume that a highly segregated educational system could have an impact on students that goes beyond academic learning.

\section{Methods}

Data

The paper uses data from the Young Lives (YL) longitudinal study. This is a study of childhood poverty that has followed around 12,000 children in Vietnam, India, Ethiopia and Peru. The study has information from three rounds of household surveys (administered in 2002, 2006 and 2009) from two cohorts of children (born in 1994 and in 2001). In this study only the younger cohort data is analyzed (in round 1, the number of subjects was 2052; see Cueto et al., 2011). Additional to the household data, YL collected school survey data in 2011 from a random sub-sample of 572 YL students of the younger cohort and 1207 peers nested in 132 schools (see Guerrero et al., 2012).

\section{Sample}

The original YL sample was selected randomly from 20 sites around the country. However, given that the focus of the study was childhood poverty, a decision was made to exclude the richest $5 \%$ districts of Peru (Escobal and Flores, 2008); for education, this meant excluding several private (for pay) schools. This has implications for this study, as the indicators of classroom composition will be underestimated given the above. From the original school sample of 572 children, we focus the current study on children who were in fourth grade at the time of data collection (328 children), and their 1177 peers (we eliminated classrooms with less than three peers; which reduced the sample in 41 children). From the 287 children remaining, we kept 272 for the analysis (5.2\% had missing data) ${ }^{1}$. These 287 children come from 100 schools, and 127 classrooms. Given the small number of schools that had more than one classroom in the sample we use the term "classroom composition" in this study. However, in schools where we had two classrooms, we did not find high variation between classrooms within schools (coefficient of variation less than 0.20 for all cases). Descriptive statistics of the sample are presented below.

\section{Procedures}

The YL's household surveys were administered at home to children and a caretaker, after agreeing to participate through a written or oral consent. These included preschool measures of abilities

\footnotetext{
${ }^{1}$ We did a missing value analysis that indicates that our missing observations are random.
} 
(see descriptions below). The school survey instruments were administered in classrooms towards the end of the 2011 school year by trained field workers. Principals, teachers, and students responded surveys and tests. The characteristics of the tests and scales are presented below.

Along with the YL children information, the School Survey gathered information from the fourth grade YL children's peers, since most of the YL children were at this grade. Information on classroom peers was also collected ${ }^{2}$. A maximum of two classrooms per school were selected.

\section{Statistical Model}

To estimate the effect of horizontal segregation (classroom composition derived from the proportion of parents with complete secondary or more) on achievement and socioemotional characteristics, we used two statistical techniques. First, we used a Random Effects Model, given the nested structure of the data. This technique allows us to have an accurate estimation of the standard errors since we control for non-observables at the classroom level. This model could be described as follows:

$Y_{i j}=\beta_{0 j}+\beta_{1 j} X_{i j}+\varepsilon_{i j}$

$\beta_{0 j}=\theta_{00}+\theta_{0 j} G_{. j}+u_{0 j}$

$Y_{i j}=\theta_{00}+\beta_{1 j} X_{i j}+\theta_{0 j} G_{. j}+\varepsilon_{i j}+u_{0 j}$

where:

$Y_{\mathrm{ij}}$ : Math/Reading Comprehension/socioemotional characteristics at age 10

$\mathrm{X}_{\mathrm{ij}}$ : Individual and family variables

$\mathrm{G}_{\mathrm{j} j}$ : Classroom variables

$\beta_{0 \mathrm{j}}, \beta_{1 \mathrm{j}}, \theta_{00}, \theta_{0 \mathrm{j}}$ : regression coefficients

$\varepsilon_{i j}, u_{0 j}$ : error term at individual and classroom level, with $\sim N\left(0, \sigma^{2}\right)$

Second, we used a Quantile Regression Model $^{3}$ in order to explore the effects of classroom composition at different points of the distribution on achievement and socioemotional characteristics. According to Koenker and Bassett (1978), the Quantile Regression Model can be expressed as:

$$
Y_{i}=\theta^{\tau}{ }_{0}+\beta^{\tau}{ }_{1} X_{i}+\theta^{\tau}{ }_{0} G_{i}+\varepsilon_{i}{ }^{\tau} \quad \text { with } \varepsilon_{i} \sim N\left(0, \sigma^{2}\right)
$$

$\mathrm{Y}_{\mathrm{i}}$ : achievement/socioemotional characteristics

$\mathrm{X}_{\mathrm{i}}$ : individual and family variables

$\mathrm{G}_{\mathrm{i}}$ : classroom variables

$\theta^{\tau}{ }_{0}, \beta^{\tau}{ }_{1}, \theta^{\tau}{ }_{0}$ : Regression coefficients of the $\tau$ th quantile

$\varepsilon_{i}{ }^{\tau}$ : Error term at individual level and each quantile

$0<\tau<1$ : Proportion of students that have scores below the quantile at $\tau$.

Then, the $\tau_{\text {th }}$ conditional quantile could be expressed as the following equation and requires that $\tau_{\text {th }}$ quantile of the error term be zero:

$$
Q^{(\tau)}\left(y_{\mathrm{i}} \mid x_{i}\right)=\theta^{\tau}{ }_{0}+\beta^{\tau}{ }_{1} X_{i}+\theta^{\tau}{ }_{0} G_{i}+Q^{(\tau)}\left(\varepsilon_{i}\right)=\theta^{\tau}{ }_{0}+\beta^{\tau}{ }_{1} X_{i}+\theta^{\tau}{ }_{0} G_{i}
$$

\footnotetext{
${ }^{2}$ Detailed information about procedures and preliminary results are reported in Guerrero, Leon, Rosales, Zapata, Freire, Saldarriaga and Cueto (2013).

${ }^{3}$ To check for robustness of the Quantile Regression results, a Quantile Regression with Random Effects was also estimated - see appendix A3.
} 
Finally, given the nested structure of the dataset (students within classrooms), we used the cluster variance estimator for the residuals in order to adjust coefficients standard errors given the covariance between students who share the same classroom in our sample (Primo et al, 2007).

\section{Variables}

We used four tests or scales as dependent variables (more details about these are included in Guerrero et al, 2012):

Reading comprehension: we used the 27 test items administered during the school survey. Items were taken from national standardized tests (i.e., Census Evaluation of 2007 and National Evaluation of 2001). The YL Study built the scores using Item Response Theory ${ }^{4}$; specifically the 1PL model was used to calculate and calibrate students's scores ${ }^{5}$. The reliability (Cronbach's Alpha) was 0.80 , and the mean was set at 300 and the standard deviation at 50 .

Mathematics: we used the 37 test items focusing on Numeracy (i.e. problem-solving and arithmetic operations). Items were taken from national standardized tests (i.e.: Census Evaluation of 2007, 2008 and 2009 and National Evaluation of 2004). Scores were built using the same procedures from reading comprehension scores. The reliability (Cronbach's Alpha) was 0.91 and the mean was set at 300 and the standard deviation of 50 .

Sense of belonging: a scale capturing how strongly students feel a part of the school. Students had to indicate if the agreed or disagreed with different statements (e.g., "I feel lonely", "I feel like an outsider") using a Likert Scale of four possible answers. Items were taken from the Program for International Student Assessment 2000 (PISA). The reliability index (Cronbach's Alpha) was 0.64, which according to Hair et al. (2006) is acceptable for exploratory research.

Security perception at school: is a scale capturing whether students feel safe at school or not (i.e., A student hit you or hurt you). Items were taken from the Progress in International Reading Literacy Study 2006 (PIRLS) and from the Second Regional Comparative and Explanatory Study 2008 (SERCE). This scale is composed of 6 items and it had a reliability index (Cronbach's Alpha) of 0.63 .

Our main independent variable is classroom composition: proportion of the parents with complete secondary education or more (we used the highest educational level of either parent) within the classroom. We decided to use this cut-off score as it provided with the best distribution of parental education (i.e., close to $50 \%$ ).

Control variables included: a. Individual and family characteristics, including gender (female), mother tongue (indigenous), age in months and cognitive skills at age 5 (a composite score made of two tests) ${ }^{6}$, the Peabody Picture Vocabulary Test (PPVT), which measures children's receptive vocabulary, and finally, the Child Development Assessment (CDA) to measure raw numeracy

\footnotetext{
${ }^{4}$ This theory is used to estimate individual abilities taking into account the item properties: difficulty, discrimination and guessing. There are three IRT models: i) One parameter: assumes that individual ability depends on item difficulty while discrimination is constant and guessing is zero across items, ii) Two parameters: assumes that individual ability depends on item difficulty and discrimination while guessing is zero across items, and iii) Three parameters: assumes that item difficulty, discrimination and guessing are different across items. For the School Survey, we used the one parameter model.

${ }^{5}$ For further details about the psychometric characteristics of the instruments, see Cueto and León (2012).

${ }^{6}$ Given the high correlation between cognitive skills at age 5 and classroom composition, we run a bivariate regression of classroom composition on cognitive skills at age 5 (cognitive skills $\mathrm{s}_{\mathrm{i}}=\alpha_{0}+\alpha_{1}$ classrooml Compositon $+\varepsilon_{\mathrm{i}}$ ), and kept the residuals since these are the Cognitive skills at age 5 uncorrelated with sclassroom composition (cognitive skills $s_{i}-\alpha_{o}-\alpha_{1}$ classroomCompositon $=\varepsilon_{i}$ ). This technique was taken from Duc (2009) and Behrman and Duc (2014) who used the residuals as explanatory variables.
} 
notions (i.e., none, more, few $)^{7}$. For family characteristics, we included mother education (complete secondary or more), wealth index at age 1 (collected in 2002, is a composite score made of three indexes: housing services, durable assets, and housing quality $)^{8}$.

b. School Characteristics, including school place of residence (rural), type of school (public) and school quality. The last variable is a composite score made up of three indexes: i) quality of school infrastructure (walls, roof and floor), ii) access to basic services (e.g., electricity, water) and iii) number of school facilities (i.e., library, teachers room, infirmary, sports playing field, room for workshops, and laboratory). We also included teacher characteristics such as gender (female), mother tongue (indigenous) and years of experience in the school as controls.

\section{Results}

\section{Sample characteristics}

Table 1 shows the characteristics of the analytical sample. The coefficient of variation (CV) compares the amount of dispersion for each variable used in our analysis. This statistic is defined as the ratio between the standard deviation and the mean; a variable with a CV higher than 0.30 indicates high dispersion. In terms of individual and family characteristics, among the sample of 10 year old children, on average, half are girls, around one fifth have an indigenous mother tongue, $30 \%$ of the children have mothers with complete secondary or more, and two thirds of the sample live in urban areas. With regards to teacher and school characteristics, children mainly attend public schools (93\%), located in urban areas (69\%) and $23 \%$ of them attend multi-grade schools (i.e., schools were one teacher has to work simultaneously in the classroom with students from different grades). The majority of children have female teachers (59\%), and a few have teachers with an indigenous mother tongue (12\%). Finally, on average, teachers have 18 years of experience teaching and have taught 11 years at the school they were at in 2011.

\section{Insert Table 1 around here}

\section{Dissimilarity across Peruvian schools}

Our first objective was to measure the heterogeneity of Peruvian classrooms across schools in terms of socioeconomic status. To account for the socioeconomic status variable, we used the proportion of parents with complete secondary or more as a proxy. From figure 1, the variable distribution peaks at the lower end and then again peaks at the higher end of the distribution (although not at the level of the first peak; however, as mentioned above the richest 5\% districts of the country were not included in the sample); the two peaks indicate that there is a concentration of low educated parents at the bottom of the distribution and then more educated parents on the other extreme. In the middle there tends to be more diversity. In other words, the low heterogeneity within classrooms in Peru occurs mostly in the extremes of the distribution.

Also, we estimated the level of dissimilarity across classrooms in relation to parents' education. We used the Duncan (D) and Hutchens (H) indexes (Duncan \& Duncan, 1955; Hutchens, 2001) to check for dissimilarities across classrooms. Both indices take values from 0 to 1 , and they are based on the dissimilarity index parameter. However, while the $\mathrm{H}$ index is a squared root index, the D index is a linear index that shows the dissimilarity of the distribution, reflecting the proportion of children with more educated parents that would have to be moved in order to make the two distributions equal. Both indices provide converging results: classrooms in our sample show high levels of dissimilarity. The $\mathrm{D}$ index was 0.53 and the $\mathrm{H}$ index was 0.30 . In other words, if we wanted individual classrooms to keep the same distribution as the full sample, we would need to move $53 \%$ of the students who have more educated parents to a classroom in another

\footnotetext{
${ }^{7}$ Cueto, Leon, Guerrero and Muñoz (2009) describe the psychometric characteristics of these instruments.

${ }^{8}$ We used the same technique of Duc (2009) and Behrman and Duc (2014) for wealth index at age 1.
} 
school in order to have an equal distribution; this suggests a highly segregated educational system. We have found no studies using these indicators for developing countries; however, Jenkins et al. (2006) used both indexes for 27 OECD countries (although they used proportion of mothers with higher education as an indicator of segregation). These countries are quite different from Peru, but as a reference, the country with the highest D and H indexes was Hungary, with 0.47 and 0.20 respectively. The lowest D index was found for Sweden and Norway $(0.23)$ and the lowest $\mathrm{H}$ index for Sweden (0.046).

\section{Insert Figure 1 around here}

Additionally, from an equity perspective it is relevant to analyze if the concentration of students with more or less educated parents has implications in terms of the educational opportunities at school. Table 2 suggests that classrooms with a higher proportion of educated parents (upper or third tercile) have more access to basic services, better school infrastructure, and more facilities at school. Also, classrooms with more educated parents are located mainly in urban areas and its population is more likely enrolled in a private (for pay) school. In terms of teacher characteristics, there is no clear pattern. On average, the groups of classrooms have similar percentages of female teachers, years of experience as a teacher in general and years of experience at the school from which the sample was taken. The only difference at the classroom level was the percentage of teachers with an indigenous mother tongue - classrooms with more educated parents do not have on average teachers with this cultural and language background.

Insert Table 2 around here

\section{The effect of classroom composition on student outcomes}

Our second objective was to explore the association between classroom composition and student outcomes. In order to explore this, we used a random effects model that allowed us to control for non-observables, and a Quantile Regression Model to explore the robustness of the effects across different points of the variable distribution. First we explored the correlation among the different dependent variables and the classroom composition measure. Table 3 shows that classroom composition has a positive association with all dependent variables ${ }^{9}$, but the association is higher with the two achievement measures and in fact is non-significant with perception of security at school. In general perception of security at school showed the lowest correlation among independent and dependent variables.

\section{Insert Table 3 around here}

For the random effect analysis, we estimated three different models: i) a bivariate model (peer effects on dependent variable), ii) a model with individual and family characteristics, and iii) a model with individual and family characteristics and school characteristics. In Table $4{ }^{10}$, we present the results of the random effects models estimated for each dependent variable. Our results for the bivariate model (Model 1) show that classroom composition has a positive and statistically significant effect for reading, mathematics and sense of belonging, but not for perception of security at school. However, once we hold individual, family characteristics (Model 2) and school characteristics (Model 3) constant, classroom composition remained statistically significant in mathematics and sense of belonging, but not in reading comprehension. Perception of security

\footnotetext{
${ }^{9}$ We estimated a bivariate regression model with cluster estimation adjustment in the variance covariance matrix in order to have correlation coefficients adjusted by the nested structure of the data. This approach was used since in a bivariate linear regression analysis, the coefficient of determination (R-square) is equal to the squared correlation coefficient between the dependent variable and the independent variable used in the analysis (Harel, 2009).

${ }^{10}$ To see all regression coefficients, go to Table A1 and A2.
} 
however turned significant $(\mathrm{p}<0.05)$ only after including covariates, which we find to be a nonconsistent result.

Also, we explored the long-term effects of wealth index at age 1 and cognitive skills at age 5 on student achievement. Wealth index was positively associated with math achievement as well as sense of belonging, while the effects on reading comprehension and perception of security at school were not significant. For cognitive skills at age 5, we found a positive and statistically significant effect on reading comprehension and math achievement, and marginally significant for sense of belonging but only in model 2; cognitive skills had no effect on perception of security at school. The fact that the wealth index and/or preschool cognitive abilities are significant predictors of mathematics and reading comprehension several years later suggests that the primary education system is unequal because it cannot compensate for socioeconomic differences or early abilities of students. Those who come from more educated family environments or who show early abilities (both of which are also correlated) are likely to score higher by the end of fourth grade.

\section{Insert Table 4 around here}

Table 5 presents the coefficients for the Quantile regression analysis for each dependent variable. Classroom composition is statistically significant for mathematics and sense of belonging at all points of the distribution $\left(25^{\text {th }}, 50^{\text {th }}\right.$ and $75^{\text {th }}$ percentile $)$ and not significant at any point for reading comprehension; however, for perception of security at school, it was statistically significant at the lower end of the distribution only $\left(25^{\text {th }}\right.$ percentile).

\section{Insert Table 5 around here}

Finally, we created case scenarios using the predicted values for Math and Sense of Belonging final models, given that these showed consistent significant effects of classroom composition. The objective of these case scenarios is to show changes in Math and Sense of Belonging scores given: wealth index at age 1 (estimated through the wealth index presented above) for children of three groups: - 1SD, Mean, + 1SD, proportion of students in the classroom who had parents with secondary education or more, and the level of achievement at the testing in 2011 for children of three groups: at the percentile 25, 50, and 75. Figure 2 presents the results for mathematics. In all cases, the math achievement score increased in a scenario were children had studied with more peers who had parents with secondary education or more. For example, a child at the lower end of the math achievement distribution $\left(25^{\text {th }}\right.$ percentile) with low wealth index (-1SD) who is attending a classroom comprised by a low proportion of educated parents (.10) will have a math achievement score of 252. The math achievement score for this student would increase in 32 points if the child had studied in a classroom where $90 \%$ of the peers had parents with more than high school.

\section{Insert Figure 2 around here}

In another case scenario, instead of children's wealth index at age 1 we used the abilities prior to entering primary school (i.e., cognitive skills at age 5). The other variables remain the same as in the above analysis. We observe a similar pattern of benefits from studying with peers who come from more educated families. For instance, a child at the median of the math achievement distribution $\left(50^{\text {th }}\right)$ with low cognitive skills at age $5(-1 \mathrm{SD})$ who is attending a classroom with a low proportion of educated parents (.10) will have a math achievement score of 270 . The math achievement score for this student would increase in 38 points if the child had studied in a classroom with the highest proportion of more educated parents. Similar results are found at the lower and upper end of the achievement distribution. 
In figure 4, the case scenario examines scenarios for students' sense of belonging (mean set at 0 ). The patterns are very similar to those found for mathematics; for example, a child at the lower end of the sense of belonging distribution $\left(25^{\text {th }}\right)$ with low wealth index (- 1SD) who is attending a classroom comprised by a low proportion of parents with secondary education or more $(0.10)$ will have a sense of belonging score of -0.92 SD. The sense of belonging score for this student would increase in $0.62 \mathrm{SD}$ if the proportion of educated parents would rise to .90 in the classroom.

\section{Insert Figure 4 around here}

Finally, in figure 5, we conducted the same exercise but for cognitive skills at age 5 instead of wealth index at age 1. Again, children who studied in classrooms with peers who had more educated parents would show a higher sense of belonging. For example, a child at the lower end of the sense of belonging distribution scores $\left(25^{\text {th }}\right)$ with low cognitive skills at age $5(-1 \mathrm{SD})$ who attended a classroom with a low proportion of educated parents $(0.10)$ would have a sense of belonging score of $-1.10 \mathrm{SD}$. This would increase in $0.63 \mathrm{SD}$ if the child studied in a classroom with a proportion of 0.90 of educated parents.

Insert Figure 5 around here

\section{Discussion}

One of the main challenges of the educational systems in developing countries is to simultaneously raise the average achievement and reduce the inequalities associated with the socioeconomic status of students. We find that the analysis of classroom and school composition is a relevant topic towards this goal, as it has been shown that socioeconomic indicators of the student body are associated with achievement but also with educational opportunities at schools (Thrupp \& Lupton, 2006).

Along these lines, in this study we have analyzed two issues around classroom and school composition in Peru, a country that has been often found to be highly unequal in regards to the achievement of its students (e.g., OECD; 2010). ${ }^{11}$ Our first objective relates with the magnitude of horizontal segregation in the Peruvian educational system, as defined by the proportion of parents in classrooms who had secondary education or more. Using the Young Lives datasets, we found that Peruvian classrooms show high indexes of segregation. The dissimilarity indexes for Peru (Duncan, 0.53; and Hutchens, 0.30) are above all the OECD countries included in a study by Jenkins, Micklewright and Schnepf (2006), even though our sample excluded the top 5\% richest districts in Peru. Furthermore, the quality of schooling was associated with segregation in a way that reinforced inequality. It is interesting however that segregation seems to occur mostly at the extremes (i.e., in classrooms that have very few parents with secondary education or more, and in classrooms that have the majority of parents with secondary education or more).

The second objective was related with the effect of classroom composition on four student outcomes. Holding the wealth index at age one and preschool abilities constant, among other controls, we find that that classroom composition is significantly associated with mathematics and sense of belonging. For both measures, we found that this effect is robust since it remains statistically significant at different parts of the score distribution. The effects however were not consistently significant for reading comprehension or perception of security at school. In regards to the two achievement measures, it is interesting that the results are not consistent for

\footnotetext{
${ }^{11}$ As mentioned above, while we use the term classroom composition given the characteristics of the sample, we found small variations between classrooms in the same schools. Thus, the results found here should be largely generalizable to schools, even though larger studies with more classrooms and grades per school would be needed to confirm this.
} 
mathematics and reading. While we cannot establish in this study the paths through which parental education could have an effect, we suggest that there may be some country variations that could explain our results. In particular, national evaluations have shown that over the past decade or so, reading levels have increased, while mathematics achievement have remained almost constant. For example, national evaluations between 2007 and 2011 (the year of this school survey) improved from $15.9 \%$ to $29.8 \%$ reaching a "sufficient" level, while the increase in mathematics went only from $7.2 \%$ to $13.2 \%$ (Cueto, 2013). Scores for Peruvian students in PISA showed a similar positive trend between 2000 and 2009 for reading comprehension, although Peru had one of the lower scores among participating countries (mostly OECD members). It may be that classroom composition matters more for mathematics, where achievement is consistently low, than for other areas where there is at least a tendency for overall improvement (like reading). This is a hypothesis however that would need to be proved empirically.

For the socioemotional measures, sense of belonging has been a topic of increasing international interest (Willms, 2003). We included it as it seemed reasonable that in a highly segregated society, studying with peers from more educated families could be associated with a sense that the students and teachers in a specific school formed a community, whereby in schools with fewer educated parents the students would not feel that they belonged. While this is a topic that would seem relevant for further studies, our results suggest that perception of security at school is not associated with classroom composition.

Overall, the above results suggest the importance of classroom and school composition as a topic for developing countries, both for its association with educational opportunities as well with student outcomes. Future studies should concentrate on understanding how parental education is relevant for some areas (i.e., mathematics and sense of belonging) and seem not so important for others (i.e., reading). Overall our results do not confirm a meta-analysis carried out on this topic that found classroom composition relevant for all subject areas (Ewijk \& Sleegers, 2010). Policy makers should also take note of these results, both to plan to collect and report periodically the level of segregation in specific educational systems, trying to reduce them overtime or otherwise taking measures to promote equal educational opportunities for all children, providing educational opportunities that match students' needs in specific contexts (Thrupp \& Lupton, 2006), and planning actions to improve achievements in areas where high segregation and low socioeconomic status accumulate; all of this should be planned to have a significant impact on reducing inequalities in opportunities and outcomes. Inequality is perhaps the biggest burden that countries in Latin America face currently. 


\section{References}

Agüero, J., \& Cueto, S. (2004). Dime con quién estudias y te diré cómo rindes: Peer Effects como determinantes del rendimiento escolar (Working paper). Consorcio de Investigación Económica y Social.

Retrieved from http://cies.org.pe/files/active/0/pm0333.pdf

Behrman, J. \& L. T. Duc (2014). Early-Childhood Growth Faltering, Post-Infancy Recovery and Educational Outcomes in Late Childhood: Evidence from Vietnam, GCC Working Paper Series, GCC 14-04.

Benavides, M., Leon, Juan \& M. Etesse (2014). Desigualdades educativas y segregación en el sistema educativo peruano: Una mirada comparativa de las pruebas PISA 2000 y 2009. Avances de Investigacion 15, GRADE, Lima, Peru.

Burke, M., \& Sass, T. (2008). Classroom peer effects and student achievement (Working paper No. 18). Federal Reserve Bank of Boston National Center for Analysis of Longitudinal Data in Education Research.

Caldas, S. J., \& Bankston, C., III. (1997). Effect of school population socioeconomic status on individual academic achievement. Journal of Educational Research, 90(5), 269-277.

Coleman, J. S., Campbell, E. Q., Hobson, C. J., McPartland, J., Mood, A. M., Weinfield, F. D., \& York, R. L. (1966). Equality of educational opportunity. Washington, DC: U.S. Government Printing Office.

Cueto, S., Leon, J., Guerrero, G., \& Muñoz, I. (2009). Psychometric characteristics of cognitive development and achievement instruments in Round 2 of Young Lives. Young Lives (Technical Note No. 15). University of Oxford.

Cueto, S., \& Leon, J. (2012). Psychometric characteristics of cognitive development and achievement instruments in Round 3 of Young Lives. Young Lives (Technical Note No. 25). University of Oxford.

Duarte, J., Bos, M. S., \& M. Moreno (2010). "Inequity in School Achievement in Latin America: Multilevel Analysis of SERCE Results According to the Socioeconomic Status of Students." Inter-American Development Bank.

Duncan, O. D., Duncan B. (1955). A methodological analysis of segregation indices. American Sociological Review 20(2), 210-217

Escobal J. \& Flores, E. (2008). Technical Note 3. An Assessment of the Young Lives Sampling Approach in Peru. Oxford: Young Lives.

Ewijk, R. van \& Sleegers, P. (2010). The effect of peer socioeconomic status on student achievement: A meta-analysis. Educational Research Review, 5(2), 134-150.

Fernández, T. (2003). Tres estudios sobre determinantes sociales del rendimiento. México: Instituto Nacional para la Evaluación de la Educación.

Guerrero, G., Leon, J., Rosales, E., Zapata, M., Freire, S., Saldarriaga, V., \& Cueto, S. (2013). Young Lives School Survey in Peru: Design and Initial Findings. Young Lives (Working Paper NO 92). University of Oxford.

Hair, J.E., Anderson, R.E., Tatham, R.L., \& Black, W.C. (2006). Multivariate Data Analysis. $5^{\text {th }}$ Ed. Prentice Hall, Upper Saddle RiveR.

Hanushek, E., Kain, J., Markman, J., \& Rivkin, S. (2003). Does peer ability affect student achievement? Journal of Applied Econometrics, 18(5), 527-544.

Harel, O. (2009). The estimation of R 2 and adjusted R 2 in incomplete data sets using multiple imputation. Journal of Applied Statistics, 36(10), 1109-1118.

Hutchens, R. M. (2004). One Measure of Segregation, International Economic Review. 45(2), 555-578.

Jenkins, S., Micklewright, J., \& Schenepf, S. (2006). Social segregation in secondary schools: how does England compare with other countries? (Working paper A06/01). Institute of Social and Economic Research.

Koenker, R., \& Basset G., (1978). Regression Quantiles. Econometrica. 46(1), 33-50.

Le Thuc, Duc (2009) The Effect of Early Age Stunting on Cognitive Achievement Among Children in Vietnam, Working Paper 45, Oxford: Young Lives 
McEwan, P. (2003). Peer effects on student achievement: evidence from Chile. Economics of Education Review, 22, 131-141.

OECD (2010). Overcoming social background. Equity in learning opportunities and outcomes: Results from PISA 2009. Paris: OECD.

Retrieved from http://dx.doi.org/10.1787/9789264091450.

Opdenakker, M., \& van Damme, J. (2001). Relationship between school composition and characteristics of school process and their effect on mathematics achievement. British Educational Research Journal, 27 (4), 407-432.

Primo, D. M., Jacobsmeier, M., \& Milyo, J. (2007). Estimating the Impact of State Policies and Institutions with Mixed-Level Data. State Politics \& Policy Quarterly, 7, 446-459.

Rangvid, B. S. (2003). Educational peer effects. Quantile regression evidence from Denmark with PISA 2000 data. Chapter 3 in Do schools matter? PhD Thesis. Aarhus, Denmark: Aarhus School of Business.

Schady, N. (2011). Parents' education, mothers' vocabulary, and cognitive development in early childhood: longitudinal evidence from Ecuador. American Journal of Public Health, 101(12), 2299-2307.

Thrupp, M., Lauder, H., \& Robinson, T. (2002). School composition and peer effects. International Journal of Educational Research, 37, 483-504.

Thrupp, M. \& Lupton, R. (2006). Taking school contexts more seriously: The social justice challenge. British Journal of Educational Studies, 54(3), 308-328.

Willms, J.D., 2003. Student Engagement at school. A sense of Belonging and participation Results From PISA 2000, OCDE. From <http://www.oecd.org/ dataoecd/42/35/33689437.pdf>.

Willms, D. (2010). School composition and contextual effects. Teachers College Record, 112(4), 1008-1037.

Zimmer, R., \& Toma, E. (2000). Peer effects in private and public schools across countries. Journal of Policy Analysis and Management, 19(1), 75-92. 
Annex. Regression Coefficients

Insert Table A1. Around here

Insert Table A2. Around here

Insert Table A3. Around here 